\title{
Intrathecal IgG synthesis in relapsing-remitting multiple sclerosis (MS) is decreased by natural human alpha interferon
}

\author{
William A. Sheremata ${ }^{1}$, Alan Sazant ${ }^{1,2}$, Vincent Riesgo ${ }^{1}$, Alex Burns ${ }^{3}$ \\ ${ }^{1}$ Miller School of Medicine, MS Center of Excellence, University of Miami, Coral Gables, USA \\ ${ }^{2}$ Jackson Memorial Hospital, Miami, USA \\ ${ }^{3}$ Life Sciences Inc., St. Petersburg, USA \\ Email: wsherema@med.miami.edu
}

Received 19 April 2013; revised 26 May 2013; accepted 10 June 2013

Copyright (C) 2013 William A. Sheremata et al. This is an open access article distributed under the Creative Commons Attribution License, which permits unrestricted use, distribution, and reproduction in any medium, provided the original work is properly cited.

\begin{abstract}
Intrathecal IgG synthesis (IT IgG Syn) is an established biomarker used for the diagnosis of multiple sclerosis (MS). Earlier studies used this biomarker to assess the impact of $\mathbf{2}$ different synthetic forms of interferon alpha (IFN- $\alpha$ ) in chronic progressive MS. Unexpectedly, IT IgG synthesis was increased by this treatment. For the first time, we have assessed this parameter in relapsing-remitting patients to measure the impact of natural IFN- $\alpha$ treatment in a doseranging study in six dosage groups $(5,10,15,20,25$, $\& 30$ MIU). We have found that IFN- $\alpha$ normalized IT IgG Synthesis at 12 weeks treatment for all dosage groups. Two weeks after stopping IFN- $\alpha$ results rose slightly. At 52 weeks, 28 weeks after stopping IFN-a results revealed cessation of IT IgG Synthesis in half of the patients (15, 20, 25 MIU weekly). These results reflect different outcomes for relapsing-remitting patients vs. chronic progressive patients. They may, however, reflect differences in the biological properties of the interferon products used. An optimal range of dosage with natural human IFN- $\alpha$ dosage for MS is suggested by the results.
\end{abstract}

Keywords: Multiple Sclerosis; Interferon-Alpha; Intrathecal-IgG Syntesis

\section{INTRODUCTION}

Tourtellotte established intrathecal IgG synthesis (IT IgG Synthesis) as an important biomarker for the presence inflammatory disease within the intrathecal compartment [1]. Synthesis rates derived from the Tourtellotte formula are typically " $0 " \pm 3 \mathrm{mg} / 24 \mathrm{hrs}$. Rates are rarely in- creased in non-inflammatory central nervous system (CNS) disease. Measurement of IT IgG synthesis is now established as important in the diagnosis of multiple sclerosis (MS) [2]. Oligoclonal bands found in cerebrospinal fluid (CSF) also reflect intrathecal IgG synthesis but do not easily lend to quantification. Despite the ability to accurately measure low concentrations of IgG in CSF, determination of IT IgG Synthesis has been rarely used to evaluate therapeutic responses in MS. Ideally a therapy, if successful, might be expected to reduce or eliminate $\mathrm{IgG}$ synthesis. The first use of natural human interferon alpha (IFN- $\alpha$ ) in a prospective therapeutic trial in relapsing-remitting MS was reported by Knobler in 1984 [3]. A salutary outcome far outlasted the 6 months of active drug administration [4]. This trial was later followed by additional trials, employing two different forms of interferon- $\alpha$, where IT IgG Synthesis was measured.

Lymphoblastoid interferon alpha (Wellferon ${ }^{\circledR}$ ), used in a trial that included only "chronic progressive" MS patients, was unexpectedly found to increase IT IgG Synthesis [5]. In another report, recombinant interferonalpha-2b, (IFN- $\alpha-2 b)$ was limited to "chronic progresssive" MS. This trial also resulted in increased IT IgG Synthesis in 4 of 6 patients and was also associated with a negative clinical outcome [6]. In contrast, our initial observations in relapsing-remitting MS patients revealed an apparent decrease in IT IgG Synthesis following natural IFN- $\alpha$ administration. Our experience with different sources of highly purified natural human IFN- $\alpha$ in trials and off-label use [7] has shown them to be generally well tolerated and seemingly effective; in keeping with the outcomes of the trial reported by Knobler et al $[3,4]$. In an IRB approved dose ranging therapeutic trial of highly purified IFN- $\alpha$ in relapsing-remitting (RRMS), 
we prospectively collected and stored serial serum and CSF laboratory specimens for subsequent IT IgG Synthesis measurement.

\section{METHODS \& MATERIALS}

Interferon-alpha (IFN- $\alpha$ ); specific (antiviral) activity more than one log greater than "Cantell Standard" $\left(10^{6}\right.$ international units (IU)/mg protein) [8] was provided by Life Sciences, St. Petersburg Florida in frozen sterile ampoules containing 5 MIU each, for subcutaneous administration.

Patient Population; Study subjects were selected from the University of Miami Multiple Sclerosis Center patient population, after completion of IRB approved informed consent. A total of 24 RRMS patients were entered into a dose ranging study to examine the tolerability and safety of IFN- $\alpha$ (Life Sciences, St. Petersburg Florida).

Clinically indicated examinations of CSF are regularly performed at our center, as a standard of care. All 24 relapsing patients recruited into the study (Table 1) had been clinically stable for at least 2 months prior to entry and had not received any form of drug treatment includeing steroids and antibiotics in that time period. At study entry, all patients agreed to subsequent lumbar punctures for CSF examination at 12, 26, and 52 weeks. They were re-consented prior to each subsequent procedure. All patients underwent clinical evaluations with documented disability status at entry and every 3 months during the year of study. Blood draws were planned to coincide and to accompany CSF submitted for subsequent IT IgG Synthesis determination. Patient were provided standard of care.

Patient Demographics: Mean age of onset was $29.6 \pm$ 6.5 years (range 19 - 40 years). Mean age at entry was $37.4 \pm 7.8$ years (range $20-50$ years). Sex ratio was 19 females: 5 males. All were Caucasian. All were relapsing but 7 required an assistive device to walk at the time of study entry.

\subsection{Randomization}

Patients were randomized to one of six IFN- $\alpha$ dosage groups. These groups received weekly total doses (Millions International Units; MIU of IFN- $\alpha$ ): 5, 10, 15, 20, 25 , or 30; in divided subcutaneous injections $3-6$ times weekly. Treatment was planned for 24 weeks. There were no placebo recipients.

\subsection{IT IgG Synthesis Determination}

Serum and CSF albumin (ALB) and IgG concentration were determined using batched stored specimens. Testing was performed in quadruplicate, in blinded fashion, using high quality immunodiffusion plates (Hoechst-
Table 1. Demographics for $24 \mathrm{MS}$ patients entered into the dose ranging trial of INF- $\alpha$.

\begin{tabular}{|c|c|c|c|}
\hline Age at Onset & Age at Entry & Sex & IFN- $\alpha$ Dose \\
\hline 33 & 50 & $\mathrm{~F}$ & 5 \\
\hline 32 & 40 & $\mathrm{~F}$ & 5 \\
\hline 24 & 40 & M & 5 \\
\hline 25 & 28 & M & 5 \\
\hline 29 & 36 & $\mathrm{~F}$ & 10 \\
\hline 37 & 58 & $\mathrm{~F}$ & 10 \\
\hline 27 & 31 & $\mathrm{~F}$ & 10 \\
\hline 40 & 41 & $\mathrm{~F}$ & 10 \\
\hline 33 & 36 & $\mathrm{~F}$ & 15 \\
\hline 19 & 41 & $\mathrm{~F}$ & 15 \\
\hline 23 & 33 & $\mathrm{~F}$ & 15 \\
\hline 40 & 41 & $\mathrm{~F}$ & 15 \\
\hline 19 & 40 & $\mathrm{~F}$ & 20 \\
\hline 31 & 32 & $\mathrm{~F}$ & 20 \\
\hline 37 & 38 & $\mathrm{~F}$ & 20 \\
\hline 25 & 34 & M & 20 \\
\hline 30 & 31 & $\mathrm{~F}$ & 25 \\
\hline 39 & 40 & $\mathrm{~F}$ & 25 \\
\hline 29 & 31 & $\mathrm{~F}$ & 25 \\
\hline 31 & 46 & M & 25 \\
\hline 22 & 27 & $\mathrm{~F}$ & 30 \\
\hline 28 & 29 & $\mathrm{~F}$ & 30 \\
\hline 20 & 25 & $\mathrm{~F}$ & 30 \\
\hline 37 & 49 & $\mathrm{~F}$ & 30 \\
\hline Mean $=29.6$ & Mean $=37.4$ & $19 \mathrm{~F}: 5 \mathrm{M}$ & \\
\hline \pm 6.5 Years & \pm 7.8 Years & & \\
\hline
\end{tabular}

Boehringer Ingelheim). Calculation of IT IgG Synthesis expressed as $\mathrm{mg} \operatorname{IgG} / 24 \mathrm{hrs}$.) was determined using the Tourtellotte formula [1]:

$\left[\left(\mathrm{IgG}_{\text {-CSF }}-\mathrm{IgG}_{\text {-SERUM }} / 369\right)-\left(\mathrm{ALB}_{\text {-CSF }}-\mathrm{ALB}_{\text {-SE-RUM }}\right)\right.$ $\mathrm{X}$ IgG-SERUM $/$ ALB-SERUM $)(0.43)] \times 5$.

The established normal range for the laboratory was $-3 \mathrm{mg} / 24 \mathrm{hrs}$. to $4.1 \mathrm{mg} / 24 \mathrm{hrs}$.

\section{RESULTS}

\subsection{Patient Retention \& Specimen Collection}

Serum and CSF were collected in all 24 subjects prior to IFN- $\alpha$ administration. At 12 weeks, 24 subjects con- 
sented to their second study CSF examination. However, at week 13, four subjects ended their study participation (1 at 10, 1 at 15 MIU and 2 at 30 MIU weekly doses). Of the remaining 20 subjects, 19 had at least $3 \mathrm{CSF}$ examinations (19 at week 26 and 13 at week 52).

\subsection{Statistical Analysis}

Statistical Analysis for Social Sciences (SPSS) package was used for performance of analysis of variants (ANOVA) to evaluate significant different between pretreatment and 3, 6, and 12 months post-treatment. Students T-test was also used to evaluate potential differences in IT IgG Syn outcomes using the lower dosage range $(5,10,15$ MIU weekly) vs. the higher dosage range (20, 25, 30 MIU weekly) at 12 months.

\subsection{IT IgG Synthesis}

Results for dosage groups are shown in in Figure 1. For all subjects, baseline (pretreatment) mean IT IgG Synthesis rate was $43 \pm 39.6 \mathrm{mg} \mathrm{IgG} / 24 \mathrm{hrs}$. At week 12 the mean rate for the 24 decreased to $-6.3 \pm 4.1 \mathrm{mg} \mathrm{IgG} / 24$ hours $(\mathrm{p}=0.01$; ANOVA). Values increased to $5.7 \pm$
$13.6 \mathrm{mg} \mathrm{IgG/24} \mathrm{hours} \mathrm{at} \mathrm{week} 26$ weeks (NS), 2 weeks after IFN- $\alpha$ withdrawal, (19 Subjects).

At week 52, 28 weeks after stopping IFN- $\alpha$, the mean synthesis rate (13 subjects) increased to $18.6 \pm 18.4$ $\mathrm{mg} / 24$ hours. Interestingly, in 3 subgroups $(5,10$, and 30 MIU weekly) mean IT IgG Synthesis was increased at 52 weeks. However, in the 15, 20, and 25 MIU weekly groups IT IgG synthesis appeared to have stopped at 52 weeks, 28 weeks after IFN- $\alpha$ cessation. T-test compareson of the 5 - 15 MIU IFN- $\alpha$ recipients with the $20-30$ MIU recipients did not reach significance, due to the small number of values and scatter. The $15-25$ MIU IFN- $\alpha$ patient groups appeared clinically to tolerate IFN- $\alpha$ better than those receiving 30 MIU weekly.

Although IFN- $\alpha$ was well tolerated, increased MS relapses were seen in the 5 MIU group, where 3 who had received for the full 24 weeks of IFN- $\alpha$ treatment, relapsed within 6 weeks of stopping their IFN- $\alpha$ treatment. The highest 30 MIU dosage was not so well tolerated and 2 withdrew prior too 52 weeks because of adverse experience. One of these two in the $30 \mathrm{MIU}$ dose group that completed through week 52 had developed chronic progressive disease.

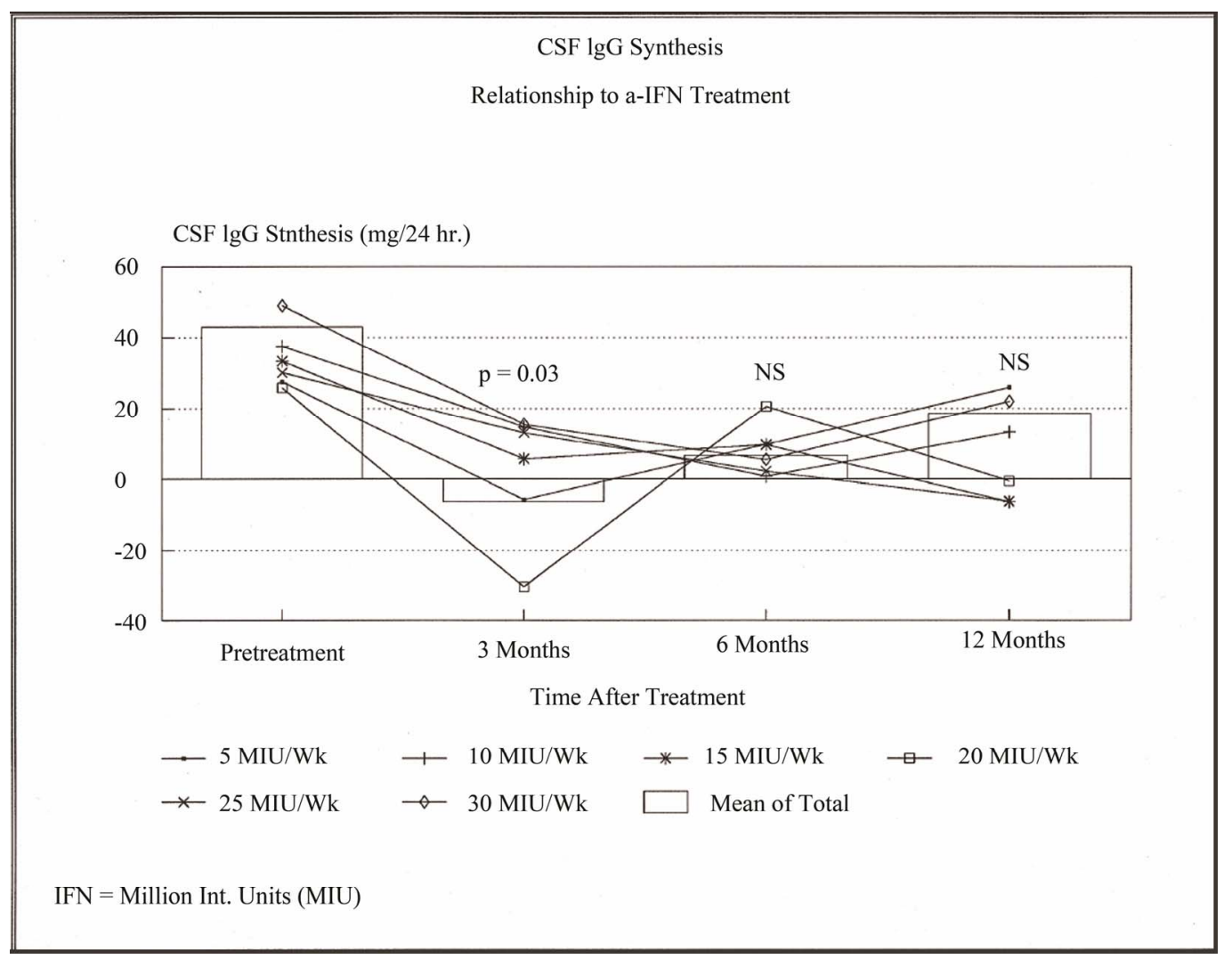

Figure 1. Intrathecal Immunoglobulin G Synthesis (IT IgG synthesis); in 24 RRMS patients treated with Interferon-alpha (IFN- $\alpha$ ) in 6 dosage groups (in MIU): 5, 10, 15, 20, 25, \& 30. Box columns show means for all 6 groups-pretreatment (24 patients); at 12 weeks of treatment (24 patients), "3" months (19 patients); and 52 weeks " 12 months" (12 patients). Line graphs for each dosage group connect mean IT IgG synthesis shown at the respective time points. 


\section{COMMENT}

We report a significant decrease of IT IgG synthesis at 12 weeks of natural human IFN-alpha (IFN- $\alpha$ ): therapy in RRMS. Although not reaching significance, values at 26 weeks, 2 weeks after stopping drug, values were much lower than those prior to treatment. Of interest, IT IgG Synthesis appeared to have ceased at 52 weeks in 3 higher dosage groups (15, 20, and 25 MIU weekly; NS). Our results clearly differ from earlier reports on the use of lymphoblastoid interferon alpha [5] and use of recombinant IFN- $\alpha-2 b$ in "chronic progressive" MS [6]. Additionally, in the lowest dosage group in the current study, 5 MIU weekly, there appeared to be a withdrawal effect with relapses and a measurable increase of IT IgG Synthesis shortly after cessation of treatment in 3 subjects. These results suggest a dosage range between 15 and 25 MIU of natural IFN- $\alpha$ may be optimal for future study.

Corticotrophin and steroids reduce IT IgG synthesis promptly but only transiently [1,9]. The only report of the impact of interferon-beta, (an Italian intrathecal interferon-beta trial), did not show clinical benefit to the patients and resulted in increased numbers of oligoclonal bands (OCB) [10]. Most recently natalizumab (Tysabri ${ }^{\circledR}$ ) was reported to decrease the number of oligoclonal bands in CSF [11]. These and other reports also suggest that increasing numbers of OCB in CSF reflects increased IgG synthesis in MS, with disease progression, despite treatment [10-13]. Data showing a correlation between increased IT IgG Synthesis and increased OCB has not been published.

Explanation of the differences in our findings from the earlier demonstration of increased IT IgG Synthesis with IFN- $\alpha$ treatment reflect at least two possible factors, operating separately or together: 1) relapsing-remitting patients have fundamentally different biological processes than progressive disease, $[14,15]$ and, 2) the synthetic interferon products differ in many respects from the highly purified natural products $[16,17]$. Numerous observations support the first explanation. However, the presence of 18 different fully glycosylated forms of interferons alpha, that comprises the natural product, may well provide an alternative explanation. Certainly, immune responses to "contaminants" like $\mathrm{C} 1 \mathrm{q}$ in natural IFN- $\alpha$ [16] could contribute to benefit from the product, or may decrease any benefit.

Clinical experience with IFN- $\alpha$ products has shown a difference in adverse experience. Previously lymphoblastoid interferon increased both serum and CSF IgG with increased IT $\operatorname{IgG}$ synthesis is associated with prominent adverse experience [18]. This type of experience was not reported with Cantell standard IFN- $\alpha$ in MS [3] nor has it occurred with natural IFN- $\alpha$ products in our trial and off-label with MS [7] and human retrovirus as- sociated myelopathy (HAM/TSP) [19]. Reasons for this difference in clinical experience with IFN- $\alpha$ are unknown. Adverse experience with higher doses in the management of hepatitis is well known $[17,20]$.

In summary, use of natural human IFN- $\alpha$ in the originnal MS trial [3] and the current clinical population was generally well tolerated. It resulted in long lasting clinical benefit in many of the subjects; particularly those receiving higher doses that appeared to result in cessation of IT IgG synthesis. Apart from the relevance to the biology of RRMS, these collective observations suggest that normalizing IT IgG synthesis in RRMS may be an effective biomarker for clinical efficacy. The measurement of IT IgG Synthesis may be an important and useful tool for selection of therapeutic products for study in RRMS such as highly purified natural human interferon alpha.

\section{REFERENCES}

[1] Tourtellotte, W.W., Staugaitis, S., Walsh, M.J., Shapshack, P., et al. (1985) The basis of intra-blood-brainbarrier IgG synthesis. Annals of Neurology, 17, 21-27. doi:10.1002/ana.410170107

[2] Polman, C.H., Reingold, S.C., Banwell, B., Clanet, M., et al. (2011) Diagnostic criteria for multiple sclerosis: 2010 revisions to the McDonald criteria. Annals of Neurology, 69, 292-302. doi:10.1002/ana.22366

[3] Knobler, R. L. S., Panitch, H., Braheny, S. L., Sipe, J. C., et al. (1984) Systemic alpha-interferon therapy of multiple sclerosis. Neurology, 32, 1273-1279. doi:10.1212/WNL.34.10.1273

[4] Panitch, H.S., Francis, G.S, Hooper, C.J., et al. (1983) Serial immunological studies in multiple sclerosis patients treated systemically with human alpha interferon. Annals of Neurology, 18, 434-438. doi:10.1002/ana.410180404

[5] Kastrukoff, L.F., Oger, J.J.-F., Tourtellotte, W.W., Sack, S.L., Berkowitz, J. and Paty D.W. (1991) Systemic lymphoblastoid interferon therapy in chronic progressive multiple sclerosis. II. Immunologic evaluation. Neurology, 41, 1936-1941. doi:10.1212/WNL.41.12.1936

[6] Kinnunen, E., Timonen, T., Pirttila, T., Kalliomaki, P. et al. (1993) Effects of recombinant alpha-2b-interferon in patients with progressive MS. Acta Neurologica Scandinavica, 87, 457-460.

[7] Sheremata, W.A. and Minagar, A. (2004) Management of Interferon-beta1b (Betaseron) failures with Interferonalfan3 (Alferon). In: Hommes, O. R. and Comi, G., Ed., Early Indicators, Early Treatments, Neuroprotection in Multiple Sclerosi, Topics in Neuroscience, Springer Verlag, Milano, 191-195. doi:10.1007/978-88-470-2117-4_20

[8] Strander, H., Cantell, H., Carlstrom, G., Jakobsson, P.A. (1973) Clinical and laboratory investigations on man: Systemic administration of potent interferon to man. 
Journal of the National Cancer Institute, 51, 733-743

[9] Miro, J., Aguayo, P., Alvarez, C., et al. (1992) Intrathecal immunoglobulin synthesis in multiple sclerosis: Effect of corticosteroids and azathioprine. European Neurology, 32, 349-353. doi:10.1159/000116859

[10] Milanese, C., Salmaggi, A., La Mantia, I., Campi, A., et al. (1990) Double blind study of intrathecal beta-interferon in multiple sclerosis: clinical and laboratory results. Journal of Neurology, Neurosurgery \& Psychiatry, 53, 354-557. doi:10.1136/jnnp.53.7.554

[11] Villar, L.M., Garcia-Sanchez, M.I., Costa-Frossard, L, Espino, M, et al. (2012) Immunological markers of optimal response to natalizumab in multiple sclerosis. Archives of Neurology, 68, 191-197. doi:10.1001/archneurol.2011.971

[12] Brandao, C.O., Ruocco. H.H., Santos Farias, A, Oliveira, C., et al. (2005) Cytokines and intrathecal IgG synthesis in multiple sclerosis patients during clinical remission. Arquivos de Neuro-Psiquiatria, 63, 914-919. doi:10.1590/S0004-282X2005000600002

[13] Ruocco, H.H., Brandao, C.O., Farias, A.S, Oliveira, E.C, et al. (2012) Quantitative MRI and cerebrospinal fluid inflammatory mediators in Brazilian patients with relapsing-remitting multiple sclerosis before and after treatment with immunomodulators: A g longitudinal study. Neuroimmunomodulation, 19, 277-282. doi:10.1159/000335889

[14] Prineas, J.W., Kwon, E.E., Cho, E.-S., Sharer, L.R., et al.
(2001) Immunopathology of secondary-progressive multiple sclerosis. Annals of Neurology, 50, 646-657. doi:10.1002/ana.1255

[15] Serafini, B., Rosicarelli, B., Magliozzi, R., Stigliano E., and Aloisi, F. (2006) Detection of ectopic B-cell follicles with germinal centers in the meninges of patients with secondary progressive multiple sclerosis. Brain Pathology, 14, 164-174.

[16] Rice, G.P.A., Woelfel, E.L., Talbot, P.J., Braheny, S.L., et al. (1985) Immunological complications in multiple sclerosis patients receiving interferon. Annals of Neurol$o g y$, 18, 439-442. doi:10.1002/ana.410180405

[17] Gaits, G. and Huber, C. (1988) The biology of interferon actions. Blut, 56, 193-199. doi:10.1007/BF00320105

[18] Kastrukoff, L.F., Oger, J.J., Hashimoto, S.L., Sacks. S.L., et al. (1990) Systemic lymphoblastoid interferon therapy in chronic progressive multiple Sclerosis. I. Clinical and MRI evaluation. Neurology, 40, 479-486. doi:10.1212/WNL.40.3 Part 1.479

[19] Sheremata, W., Harrington, W., Tornes, L., Ortega, M., McCarthy M. (2011) Therapeutic response to human interferon-alpha-n3 but failure with recombinant interferonalpha-2b in HAM.TSP. Multiple Sclerosis, 17, S280.

[20] Fattovich, G., Giustina, G., Favarato, S. and Ruol A. (1996) A survey of adverse events in 11,241 patients with chronic viral hepatitis treated with alfa interferon. Journal of Hepatology, 24, 38-47. doi:10.1016/S0168-8278(96)80184-X

\section{Abbreviations}

\author{
Abbreviation: Defined Term \\ MS: Multiple Sclerosis \\ RRMS: Relapsing-Remitting MS \\ CNS: Central Nervous System \\ CSF: Cerebrospinal Fluid \\ IT: Intrathecal \\ IgG: Immunoglobulin G \\ IFN: Interferon \\ IFN- $\alpha$ : Interferon alpha \\ MIU: Million International Units \\ mg.: milligram \\ hrs.: hours \\ mg./24 hrs.: milligrams per 24 hours [IgG Synthesis] \\ HAM/TSP: Human T-cell leukemia Associated Myelo- \\ pathy/Tropical Spastic Paraparesis \\ IRB: Institutional Research Board (Ethics Committee)
}

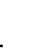

